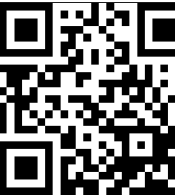

Editor's choice

Scan to access mo free content

${ }^{1}$ Department of Anaesthesia, Royal Infirmary of Edinburgh, Edinburgh, UK

${ }^{2}$ Intensive Care Unit, James Cook University Hospital, Middlesbrough, UK

\section{Correspondence to} Sqn Ldr Elise Hindle, Department of Anaesthesia, Royal Infirmary of Edinburgh, 51 Little France Crescent, Edinburgh, EH16 4SA, UK: elise.hindle@yahoo.co.uk

Received 26 March 2013 Revised 1 October 2013 Accepted 14 October 2013

Published Online First

19 November 2013

\title{
Critical care at extremes of temperature: effects on patients, staff and equipment
}

\author{
Elise M Hindle, ${ }^{1}$ J D Henning ${ }^{2}$
}

\section{ABSTRACT}

Modern travel and military operations have led to a significant increase in the need to provide medical care in extreme climates. Presently, there are few data on what happens to the doctor, their drugs and equipment when exposed to these extremes. A review was undertaken to find out the effects of 'extreme heat or cold' on anaesthesia and critical care; in addition, subject matter experts were contacted directly. Both extreme heat and extreme cold can cause a marked physiological response in a critically ill patient and the doctor treating these patients may also suffer a decrement in both physical and mental functioning. Equipment can malfunction when exposed to extremes of temperature and should ideally be stored and operated in a climatically controlled environment. Many drugs have a narrow range of temperatures in which they remain useable though some have been shown to remain effective if exposed to extremes of temperature for a short period of time. All personnel embarking on an expedition to an extreme temperature zone should be of sufficient physical robustness and ideally should have a period of acclimatisation which may help mitigate against some of the physiological effects of exposure to extreme heat or extreme cold. Expedition planners should aim to provide climatic control for drugs and equipment and should have logistical plans for replenishment of drugs and medical evacuation of casualties.

\section{INTRODUCTION}

The increasingly expeditionary nature of modern society has led to medical personnel from both military and civilian backgrounds being called upon to work in increasingly austere environments. It is now commonplace for medical facilities to accompany military operations, including those in the initial entry phase, and also civilian expeditions. When extremes of climate are predictable, it is common practice to provide climatic control in established medical facilities. ${ }^{1}$ However, accompanying medical personnel must also be prepared to provide life or limb-saving surgical and medical treatment during the initial entry phase of any expedition where such facilities are not yet constructed. With temperatures of less than $-50^{\circ} \mathrm{C}$ recorded during expeditions in Antarctica ${ }^{2}{ }^{3}$ and more than $+50^{\circ} \mathrm{C}$ in Death Valley in the USA, ${ }^{4}$ it is vital that civilian or military doctors wishing to provide medical support to expeditions understand how extremes of climate can affect their patients, equipment, drugs and themselves.

This review brings together the available evidence regarding the physiological impact of extreme heat and cold upon critically ill or injured patients and also the impact upon medical personnel. In addition, it collates data regarding the effect that extremes of temperature can have upon

\section{Key messages}

- Doctors providing medical cover to expeditions into areas of extreme temperature face unique clinical and logistical challenges.

- Physiology may be markedly disrupted by hypothermia or hyperthermia and this may impact upon management of a critically ill or injured patient.

- Expedition doctors may also find their own physical and mental functioning impaired by the extreme temperature.

- Medical equipment may malfunction at extreme temperatures and battery life may be shortened or efficiency degraded.

- Some medicines may be affected by exposure to a temperature outwith the recommended storage and usage temperature ranges.

medical equipment and drugs that are commonly used in the management of such patients. Presently this is lacking in many respects and there is a clear need for further research. It should also be remembered that such expeditions can occur at altitude, but a discussion of the effects of extreme altitude is beyond the scope of this article.

\section{METHODS}

A literature review was conducted on PubMed and Google Scholar using combinations and alternative spellings of the terms 'extreme heat', 'extreme cold', 'anaesthesia' and 'critical care'. Search results were narrowed by relevance and limited to articles written in English, and the reference sections of review articles were then searched for relevant articles. Subject matter experts and pharmaceutical and medical product companies were contacted for unpublished data.

The majority of the articles which were analysed did not define 'extreme heat' or 'extreme cold' and we therefore opted to include all articles relating either to extremes of temperature sufficient to bring about altered physiology relating to hypothermia or hyperthermia, or sufficient to cause an increase in mortality on a population scale. We also included trials in which equipment and drugs were exposed to temperatures outwith the manufacturer recommended usage and storage ranges.

\section{RESULTS}

Figure 1 demonstrates the identification and screening process for article inclusion. 


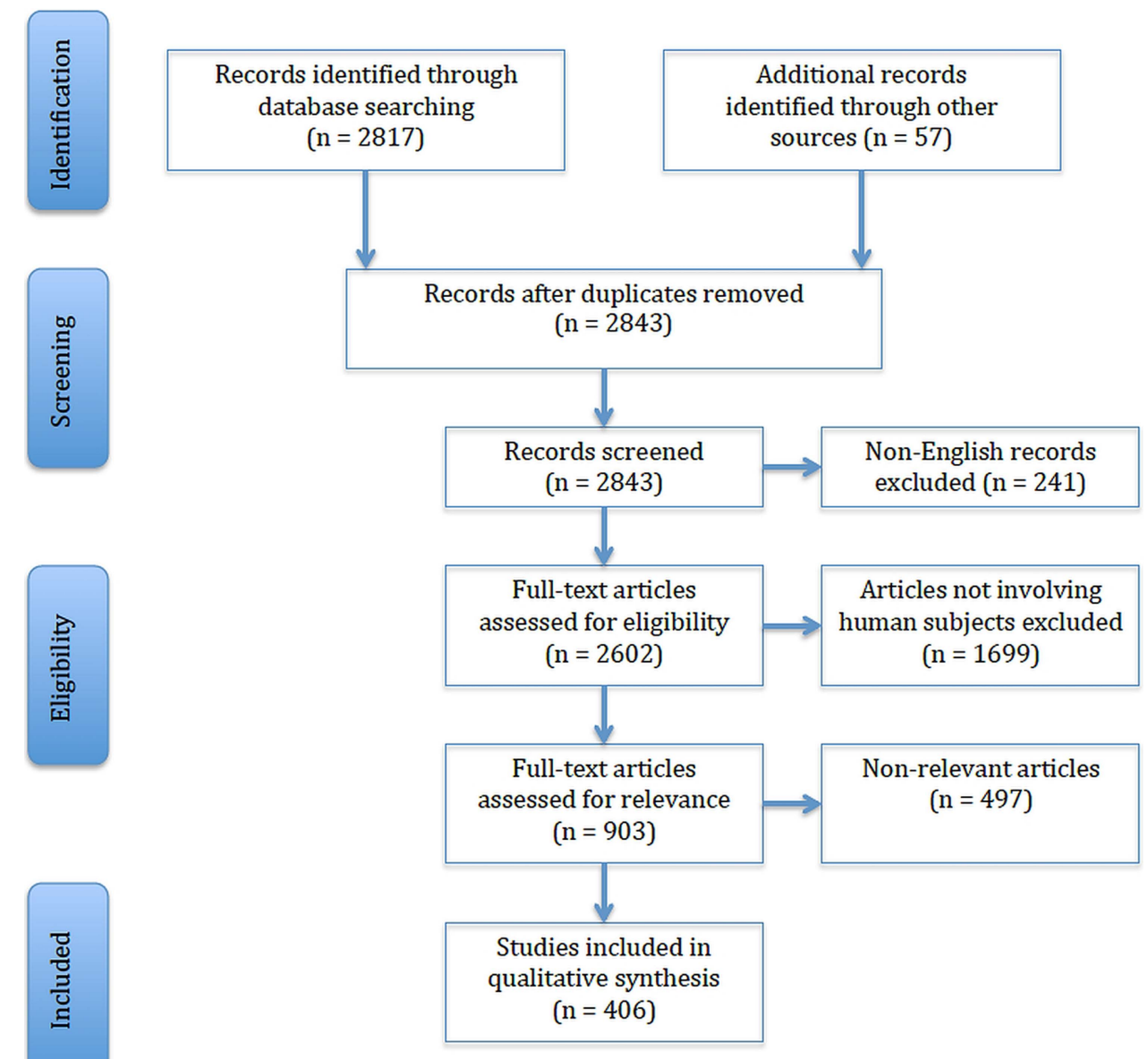

Figure 1 Systematic review flow diagram.

\section{Extreme cold}

While the physiological impact of hypothermia is well known, ${ }^{5}$ we are less accustomed to caring for patients in uncontrolled climatic environments. This unique challenge requires a keen understanding of the physiological impact of extreme cold upon the patient and on the doctors themselves.

\section{Cardiovascular system}

The cardiovascular response to hypothermia is often marked and can greatly impact upon patient morbidity. ${ }^{6}$ The response is dependent upon the degree of hypothermia with a tachycardia and hypertension being the common clinical findings of mild hypothermia and bradycardia with cardiovascular collapse secondary to poor cardiac output being more common in severe hypothermia. $^{7}$

Acute exposure to cold causes an $\alpha_{1}$-adrenoceptor-induced peripheral vasoconstriction, which can improve thermal insulation by up to $300 \% .^{8}$ This sympathetic response increases the BP by approximately $20-30 \mathrm{~mm} \mathrm{Hg}$ in young subjects and by up to $60 \mathrm{~mm} \mathrm{Hg}$ in the elderly and causes a diuresis with a reduction in plasma volume and resultant increase in blood viscosity. Cooling of the myocardium also impacts both upon the contractility and the pacemaker function of the heart. In vitro cooling of porcine myocardium to $32^{\circ} \mathrm{C}$ causes a prolongation of contraction and an increase in contractile force by almost $40 \% .{ }^{9}$ The hypertension of mild hypothermia is therefore a product of tachycardia, increased contractility and increased systemic vascular resistance. Cold-induced hypertension can be counteracted by light exercise that stimulates circulation in the lower limbs. ${ }^{5}$

As myocardial temperature drops further, spontaneous depolarisation of the pacemaker cells decreases leading to a progressive bradycardia which is refractory to atropine. The heart rate will fall to $30-40 \mathrm{bpm}$ at $28^{\circ} \mathrm{C}^{5}$ In addition, repolarisation abnormalities occur as evidenced by the appearance of an Osborn 'J' wave on the ECG. Increasingly broad QRS complexes are seen which correlate with prolonged contraction of the myocardium. Other electrocardiographic changes include ST depression and T-wave inversion. ${ }^{10}$

Many intravenous and inhalational anaesthetic agents as well as opioid analgesics diminish $\alpha$-adrenoceptor-induced vasoconstriction in a dose-dependent manner thus impairing the patient's thermoregulatory capacity and promoting heat loss. ${ }^{11} 12$

The combination of pre-existing hypothermia, loss of thermoregulatory control due to anaesthetic drugs and cool ambient temperature could lead to a rapid onset of cardiovascular compromise in a surgical or critical care patient and as such close monitoring is required.

\section{Metabolic}

The basal metabolic rate (BMR) in adults is roughly $58 \mathrm{~W} / \mathrm{m}^{2}$, which corresponds to approximately $110 \mathrm{~W}$ for a $70 \mathrm{~kg}$ male. During cold exposure, autonomic stimuli lead to shivering which can increase the metabolic rate maximally to 300-500 W. This can increase heat production fivefold, but cannot be sustained for long periods as energy reserves are exhausted. ${ }^{13}$ 
Behavioural responses to cold include increasing muscular exercise which can increase metabolic rate maximally to 1000 $1300 \mathrm{~W}$, but at a continuous work rate a level of $500 \mathrm{~W}$ is more probable. ${ }^{8}$ Most volatile and intravenous anaesthetics and opioid analgesics directly impair hypothalamic thermoregulation in a dose-dependent manner leading to a diminished threshold for shivering. ${ }^{14-16}$

An individual acclimatises to cold conditions in 2 weeks after which the physiological responses to cold are attenuated and the cold environment is considered subjectively less stressful to the individual. Acclimatisation can be insulative (increased subcutaneous fat deposits and skin vasoconstriction), hypothermic (decreased core body temperature) and metabolic (increased energy consumption). Behavioural adaptation is most effective, and in urban environments, behavioural adaptation in winter can be so effective that physiological adaptation does not occur.

Acclimatisation plays a large part in the BMR of an individual in cold conditions and also the physiological and subjective responses to cold. For example, Eskimos and the Alakaluf Indians at the southern tip of South America do not shiver in ambient temperatures of $2-5^{\circ} \mathrm{C}$ and have a BMR $30 \%-40 \%$ higher than other populations. ${ }^{17}$ Also, statistics have shown that the ambient temperature associated with the lowest annual heat-related mortality is $14^{\circ} \mathrm{C}$ in Finland, $18^{\circ} \mathrm{C}$ in South-East England and $23^{\circ} \mathrm{C}$ in South Carolina. ${ }^{18}$

The hypermetabolic state of hypothermic patients leads to increased oxygen consumption. This decreases the time to desaturation during periods of apnoea. Acclimatised subjects may demonstrate a greater degree of physiological stability under anaesthetic in those subjects who are new to the cold environment, although this remains untested.

\section{Haematological}

Even mild cold exposure can increase blood viscosity due to diuresis, ${ }^{19}$ as well as elevated cryofibrinogen levels; overall, the haematocrit increases by approximately $2 \%$ for every $1^{\circ} \mathrm{C}$ decline in temperature. ${ }^{20}$ Cold also directly inhibits the enzymatic reactions of both the intrinsic and extrinsic pathways of the clotting cascade, and a prolongation of prothrombin time, activated partial thromboplastin time and activated clotting time occurs after the development of hypothermia. ${ }^{21}$ The incidence of trauma is high in austere environments and patients may present with a coagulopathy, which can be compounded by hypothermia. ${ }^{22}$ In this circumstance, aggressive clear fluid resuscitation has been shown to worsen coagulopathy and a cautious approach to fluid resuscitation is advised. ${ }^{23}$

\section{Respiratory}

In moderate hypothermia airway reflexes can become obtunded, increasing the risk of aspiration pneumonia. ${ }^{24}$ As body temperature decreases, there is an initial tachypnoea followed by a reduction in minute volume and bronchospasm. ${ }^{25}$ This impacts upon the inhalational anaesthetic output from a draw-over vaporiser such as the one used in the Tri-Service Anaesthetic Apparatus. ${ }^{26}$ Bronchial dilation leads to an increase in physiological and anatomical dead space although alveolar dead space remains unchanged. Pulmonary vascular resistance is increased leading to a degree of ventilation-perfusion mismatch. The falling temperature leads to a left shift of the oxygen-haemoglobin dissociation curve initially; however, the resultant lactic acidosis redresses this imbalance. A lactic acidosis also occurs in response to shivering, although this will not occur if the patient has received any anaesthetic agents. ${ }^{27} \mathrm{~A}$ combined respiratory and metabolic acidosis occurs, even in the absence of shivering.
If the patient becomes severely hypothermic, this acidosis may be profound and may lead to an overall rightward shift in the oxygen-haemoglobin dissociation curve. ${ }^{28}$

\section{Renal}

A cold-induced diuresis occurs before any drop in body temperature. ${ }^{5}$ This is initially due to the increased renal blood flow that occurs as a result of peripheral vasoconstriction and increased BP; however, resistance to vasopressin (ADH) occurs at a later stage. Urine output monitoring is recommended and fluid resuscitation should be titrated to urine output and serum lactate levels where monitoring is available. ${ }^{29}$

\section{Gastrointestinal system}

As body temperature decreases, intestinal motility decreases, eventually leading to an ileus. Prolonged hypothermia also predisposes patients to peptic ulceration. ${ }^{30}$

\section{The extremely cold doctor}

With decreasing temperature, axonal conduction velocity reduces. ${ }^{31}$ As a result, moderate hypothermia causes ataxia and loss of fine motor control in its initial stages. Loss of tactile sensitivity occurs with mild hypothermia and complete nervous block occurs at a nerve temperature of $10^{\circ} \mathrm{C} .{ }^{32}$ Synovial fluid also becomes more viscous and so muscle and joint stiffness occurs. Below approximately $14^{\circ} \mathrm{C}$ skin temperature, medical personnel would suffer a significant decrement in their fine motor control and dexterity leading to an inability to operate. The wearing of bulky gloves to minimise the effects of tactile insensitivity may further impede dexterity. Again, cold adaptation plays an important role-cold adaptation of the hands can lead to diminished local vasoconstriction which allows increased circulation and skin temperatures in hands; this cold-induced vasodilatation is known colloquially as 'fisherman's hand'. ${ }^{33}$ Unfortunately, this response is not universal among subjects nor can it be trained by repeated cold exposure. ${ }^{34} 35$ It has, however been shown to occur more readily when subjects undertake endurance exercise training. ${ }^{36}$

As temperature decreases, mental capacity begins to be affected. Studies into this phenomenon can be separated into human studies in the field (polar explorers, ${ }^{37-43}$ military ${ }^{44}$ or divers ${ }^{45}{ }^{46}$ ), human studies in laboratory settings ${ }^{47}$ or animal studies. ${ }^{48}$ Allowing for variations in study design, we can draw from this evidence that subjects demonstrate an increased number of errors and changes in response time when asked to perform cognitive tests in cold conditions. Some of the studies demonstrated that these effects were particularly marked when the subjects were asked to perform complex cognitive tasks while simple tasks remained unaffected. ${ }^{8}{ }^{40}$ Also, it has been reported that individuals exposed to acute cold stress showed decrements in performance on tests involving reasoning skills. ${ }^{41}$

Impairment of short-term memory was reported even after brief cold exposures and some research has reported decrement in memory recall. ${ }^{40}$ Coleshaw et al ${ }^{49}$ demonstrated that test subjects could only recall $70 \%$ of facts learnt when body temperature was reduced to levels below $34-35^{\circ} \mathrm{C}$.

Compounding the decrement in mental capacity, many authors believe that cold exposure also has a deleterious effect upon mood. Experimental data to support this hypothesis are scant; however, there are numerous published reports of increases in depressive symptoms during the winter months in personnel on polar expeditions and based in Antarctic research stations, ${ }^{38-39}$ 50-52 known as the 'winter-over syndrome'. Without clear experimental data, it is difficult to elucidate to 
what degree these symptoms are related purely to cold exposure as it is highly likely that disruption to circadian rhythms due to continuous darkness has an impact. Rauch and Lieberman ${ }^{53}$ demonstrated behavioural depression in rats that were exposed to hypothermic conditions and postulated that this was due to a reduction in brain norepinephrine levels.

The variability in study design, duration of exposure, type of clothing and measures of temperature make it difficult to discern the precise nature of the cognitive impairment which is experienced by subjects who are required to work in extreme cold. Similarly, few studies have looked at acclimatisation to cold and performance markers. As is the case in any harsh environment, working in extreme cold requires increased vigilance and attention to detail on the part of a doctor. The available evidence leads us to conclude that an expedition doctor would be likely to find reasoning, decision making and complex tasks significantly more difficult in the extreme cold. Where possible, checklists should be employed and medical staff should try to work in teams to decrease the likelihood of clinical errors. Medical staff should also be rotated at regular intervals to allow for sufficient rest and rewarming, and all staff should be warned to be alert to the possibility of mental decrement in their colleagues at low temperatures.

The maintenance of a normal body temperature for both patient and doctor should be prioritised to mitigate against the deleterious effects of extreme cold. Transfer of the patient to a climate controlled medical facility should occur as soon as is practicable to reduce further heat loss.

\section{Extreme heat}

The last two Gulf Wars and the campaigns in Afghanistan have provided a wealth of experience in the care of critically ill or injured patients in extreme heat. Over this period of time, there has also been an increase in the number of medical facilities provided by non-governmental organisations in war-torn or drought-starved areas. Patients with a critical illness or injury who are being managed in an extremely hot environment are under a unique physiological demand. The stresses placed upon the doctor and other medical personnel are also severe.

\section{Cardiovascular system}

As the temperature increases, the autonomic nervous system via the hypothalamus causes a peripheral vasodilation in an attempt to lose heat. ${ }^{54}$ This may lead to translocation of the blood to the periphery and a drop in mean arterial pressure. Heat stroke sufferers have been noted to have raised levels of nitric oxide which may contribute to this effect. ${ }^{55}$ The addition of an anaesthetic agent will compound the situation and may lead to profound hypotension.

Sufferers of heat stroke are frequently noted to have tachyarrhythmias, which may be an exaggeration of the baroreceptor response to this hypotension. The ECG can also be affected in extreme heat with rhythm disturbances, conduction defects and ST segment changes with prolongation of the Q-T interval being the commonest finding. These changes can often be effectively treated with cooling but may persist and may be related to hypocalcaemia, hypokalaemia or hypomagnesaemia. ${ }^{56}$

Subjects exposed to extreme heat suffer a variety of electrolyte disturbances related to sweat losses and heat-induced hyperventilation. ${ }^{57}$ Hypokalaemia is common in the early stages of heat stroke but in the later stages hyperkalaemia is more often seen following cellular leakage of potassium. ${ }^{58}$ Sweat losses also lead to salt and water depletion and these should be actively replaced with the prediction of further losses if the temperature cannot be controlled. ${ }^{59}$

\section{Nervous system}

The central nervous system is particularly vulnerable to heat, the cerebellum being the most susceptible. As a result, subjects exposed to extreme heat may present with neurological impairment of varying severity and the minimum alveolar concentration of an inhaled anaesthetic agent required to maintain anaesthesia is reduced. ${ }^{60}$ The increase in temperature will also impact upon the activity of various enzyme systems in the body and may lead to alterations in the duration of action of several anaesthetic drugs. ${ }^{61}$

\section{Renal system}

In an environment of extreme heat, it is possible to have a direct thermal injury to the kidneys and also pre-renal insults such as volume depletion, rhabdomyolysis and disseminated intravascular coagulation have a higher incidence. ${ }^{62}$ These are all recognised causes of acute renal failure in exertional heat stroke. ${ }^{63}$ In the critically ill patients, there may be additional insults to renal function and as such urine output monitoring is recommended for all patients and adequate fluid resuscitation is of paramount importance. ${ }^{57}$

\section{The extremely hot doctor}

Performance in extreme heat has been studied in great depth, particularly by military researchers. The influence of climate on psychomotor skills and physical performance was assessed by Mackworth $^{64}$ at the Cambridge Psychological Unit in 1950. He assessed the ability of unacclimatised service personnel to perform three tasks at different climates. The tests were a simple manual dexterity test, a task requiring concentration and physical effort (pursuitmeter test) and finally a mental task of receiving wireless telegraphy messages in Morse code. During the test, the personnel were subjected to a range of dry bulb and wet bulb temperatures $\left(85-105^{\circ} \mathrm{F}\right.$ and $75-95^{\circ} \mathrm{F}$, respectively) in an air movement speed of $100 \mathrm{ft} / \mathrm{min}$. Climate made no difference to the performance of the manual dexterity test; in the pursuitmeter test, severe decrement occurred in temperatures exceeding dry bulb $95^{\circ} \mathrm{F}$ and wet bulb $85^{\circ} \mathrm{F}$. In the wireless telegraphy test, there was a statistically significant decrease in performance in climates hotter than $95^{\circ} \mathrm{F}$ dry bulb and $85^{\circ} \mathrm{F}$ wet bulb. Mackworth's study also demonstrated that those of greatest competence suffered less detriment at extreme temperatures.

There is little agreement on the effect of acclimatisation upon cognitive functioning in extreme heat. Ramsey and Dayal, reviewed the available evidence in 1975 and concluded that while acclimatisation clearly plays a role in improving task function during prolonged mild thermal stress, the evidence for such an effect in extremes of heat was lacking. ${ }^{65}$

When planning an expedition to an area of extreme heat, the medical team should be as experienced as possible. If novice expedition doctors are forming a part of the medical team, they should be supervised by a more experienced member of staff. A decrease in clinical abilities is predictable at high temperatures and if possible a wet and dry bulb thermometer should be included in the medical kit to monitor the working environment. When temperatures are in excess of $95^{\circ} \mathrm{F}\left(35^{\circ} \mathrm{C}\right)$ dry bulb, staff should be reminded to optimise their hydration and highrisk activities which might lead to an increased likelihood of casualties should be minimised where possible. A period of acclimatisation prior to the expedition may lead to improved 
Table 1 Equipment operating and storage temperatures (from manufacturers' operating manuals)

\begin{tabular}{|c|c|c|}
\hline Equipment & Operating temperature range & Storage temperature range \\
\hline $\begin{array}{l}\text { Braes LTV } 1000 \text { light transport } \\
\text { ventilator }\end{array}$ & 5 to $40^{\circ} \mathrm{C}$ & -20 to $+60^{\circ} \mathrm{C}$ \\
\hline Teledyne oxygen analyser & 0 to $40^{\circ} \mathrm{C}$ & 10 to $30^{\circ} \mathrm{C}$ (continuous) or 5 to $50^{\circ} \mathrm{C}$ (intermittent) \\
\hline $\begin{array}{l}\text { Corpuls } 3 \text { monitor/defibrillator } \\
\text { Batteries: lithium/ion }\end{array}$ & 0 to $45^{\circ} \mathrm{C}$ & -20 to $+65^{\circ} \mathrm{C}$ \\
\hline LSU laerdal suction unit & $\begin{array}{l}0 \text { to } 40^{\circ} \mathrm{C} \text { although } 15 \text { to } 25^{\circ} \mathrm{C} \\
\text { optimal for charging }\end{array}$ & 0 to $40^{\circ} \mathrm{C}$ (long-term) or -30 to $+60^{\circ} \mathrm{C}(\max 24 \mathrm{~h})$ \\
\hline $\begin{array}{l}\text { BBraun perfusor syringe driver } \\
\text { Battery: rechargeable } \mathrm{NiMH}\end{array}$ & 5 to $40^{\circ} \mathrm{C}$ & -20 to $+55^{\circ} \mathrm{C}$ \\
\hline $\begin{array}{l}\text { BBraun infusomat } \\
\text { Battery: rechargeable NiMH }\end{array}$ & 10 to $40^{\circ} \mathrm{C}$ & -20 to $+55^{\circ} \mathrm{C}$ \\
\hline $\begin{array}{l}\text { I-STAT blood gas analyser } \\
\text { Batteries: } 2 \text { X } 9 \mathrm{~V} \text { lithium or alkaline }\end{array}$ & 16 to $30^{\circ} \mathrm{C}$ & $\begin{array}{l}\text { Cartridges must be stored at between } 2 \text { and } 8^{\circ} \mathrm{C} \text {. Once removed from the fridge must be stored } \\
\text { at between } 18 \text { and } 30^{\circ} \mathrm{C} \text { and used within } 14 \text { days or } 2 \text { months depending on the cartridge type }\end{array}$ \\
\hline $\begin{array}{l}\text { Medtronic single chamber temporary } \\
\text { pacemaker }\end{array}$ & 10 to $43^{\circ} \mathrm{C}$ & -40 to $+70^{\circ} \mathrm{C}$ \\
\hline $\begin{array}{l}\text { Fisher and Paykel peripheral nerve } \\
\text { stimulator }\end{array}$ & 0 to $35^{\circ} \mathrm{C}$ & -25 to $+40^{\circ} \mathrm{C}$ \\
\hline $\begin{array}{l}\text { Inditherm heating mattress } \\
\text { Mains operated only }\end{array}$ & -40 to $+55^{\circ} \mathrm{C}$ & -10 to $+55^{\circ} \mathrm{C}$ \\
\hline $\begin{array}{l}12 \mathrm{Amp} / \mathrm{h} \text { battery-Panasonic LC } \\
\text { valve regulated lead acid }\end{array}$ & -20 to $+50^{\circ} \mathrm{C}$ & $-20-+50^{\circ} \mathrm{C}$ \\
\hline $\begin{array}{l}48 \mathrm{Amp} / \mathrm{h} \text { battery-valve regulated } \\
\text { lead acid industrial battery }\end{array}$ & -20 to $+50^{\circ} \mathrm{C}$ & -20 to $+50^{\circ} \mathrm{C}$ \\
\hline Datex monitor & 0 to $40^{\circ} \mathrm{C}$ & -30 to $+50^{\circ} \mathrm{C}$ \\
\hline Vela ventilator & 5 to $40^{\circ} \mathrm{C}$ & - \\
\hline
\end{tabular}

concentration and situational awareness and could potentially result in fewer clinical errors.

\section{EQUIPMENT AND DRUGS AT EXTREMES OF TEMPERATURE}

Medical equipment carried by expeditionary medical teams is highly variable and each team must be aware of the safe operating temperatures of their own equipment. When planning to provide medical care in an austere environment, it is vital to provide temperature monitoring for drugs and equipment at all times, and this must be regularly audited. The majority of medical equipment has not been tested to the extremes of temperature and therefore the safe operating or storage temperature range supplied by the manufacturer may be quite narrow. Table 1 provides examples of the operating and storage temperatures quoted in the operating manuals of equipment used by British military medical teams.

In general, most equipment will continue to function when exposed to extreme temperatures for a short period of time. Even if the equipment continues to function the screens may not, as they will often shut down as a protective measure when they get hot, and crystals in the screen can freeze and burst at low temperatures. The emission spectrum of LEDs is affected by temperature, but this has been found to not have any clinical relevance. Prolonged or repeated exposures to thermal stress will lead to rapid degradation of electronic equipment. In addition, a rapid increase in the temperature of a piece of equipment (eg, when being carried from an extremely cold environment into a climatically controlled one) can lead to internal condensation and disruption of circuitry.

Batteries function most efficiently with optimal service life if used at room temperature $\left(20^{\circ} \mathrm{C}\right)$; however, an increase in temperature will improve a battery's performance for a short period of time due to a lowering of the internal resistance and speeding up of chemical metabolism. This improved performance comes at the cost of a decrease in the working life of the battery and so users should avoid exposing batteries to high temperatures for prolonged periods. Cold temperatures lead to increased internal resistance and a diminished performance. Batteries that would provide $100 \%$ capacity at $27^{\circ} \mathrm{C}$ will typically deliver only $50 \%$ capacity at $-18^{\circ} \mathrm{C}$ and at $-20^{\circ} \mathrm{C}$ most nickel, lead or lithium-based batteries will stop functioning.

Most field anaesthetic machines employ a draw-over vaporiser fitted with temperature compensation mechanisms. These are only effective to a certain degree and at extremes of temperature the output of such vaporisers will be highly variable. This should be taken into consideration if inhalational anaesthesia is required. In extreme cold environments, it may be that the whole vaporiser needs to warmed up prior to use (eg, in a water bath). It should also be remembered that in the tropics the filling ratio of vapour cylinders is lower, therefore they may contain less than expected. Disposable medical apparatus which is formed from poly-vinyl chloride such as endotracheal tubes, oxygen face masks and tubing may become exceedingly malleable at extremely high temperatures leading to a risk of kinking or may become brittle at extremely low temperatures.

Failure to follow storage recommendations of pharmaceutical products could potentially result in therapeutic failure. However, it may be extremely difficult to avoid exposing drugs to some degree of thermal stress when transporting them to a medical centre located in an austere environment. Prolonged storage of drugs at high or low temperatures risks denaturation of proteins and alterations in product characteristics. It is therefore advisable when working in an extreme environment to preferentially stock drugs which are stable at a wide range of temperatures, for example, atropine and lidocaine (stable between -20 and $+70^{\circ} \mathrm{C}^{66}$ ) rather than those which must be kept within a narrow thermal range. If such drugs are to be carried they will generally be stored in a temperature controlled 


\begin{tabular}{|c|c|c|}
\hline Drug & Effective after heat stress & Effective after cold stress \\
\hline Adenosine & Yes & (Yes) \\
\hline Epinephrine & Yes & Yes \\
\hline Amiodarone & - & Yes \\
\hline Atropine & Yes & Yes \\
\hline Clonidine & - & Yes \\
\hline Diazepam & Yes* & (Yes) \\
\hline Digoxin & - & - \\
\hline Dobutamine & Yes & Yes \\
\hline Dopamine & Yes & - \\
\hline Fentanyl & Yes & (Yes) \\
\hline Furosemide & Yes & Yes \\
\hline Glucose $40 \%$ & Yes & Yes \\
\hline Heparin & (Yes) & (No) \\
\hline Insulin & (Yes) & No \\
\hline Ringer lactate & Yes & Yes \\
\hline Ketamine & Yes & Yes \\
\hline Lidocaine & Yes & Yes \\
\hline Metoprolol & Yes & Yes \\
\hline Midazolam & Yes & Yes \\
\hline Morphine & Yes & - \\
\hline Naloxone & Yes & Yes \\
\hline Norepinephrine & Yes & - \\
\hline Pancuronium & (Yes) & No \\
\hline Suxamethonium & (Yes) & Yes \\
\hline Thiopental & Yes & Yes \\
\hline Vecuronium & Yes & Yes \\
\hline Verapamil & Yes & Yes \\
\hline \multicolumn{3}{|c|}{$\begin{array}{l}\text { Heat stress is defined as exposure to a temperature of } 60^{\circ} \mathrm{C} \text { for a period of several } \\
\text { hours and cold stress is defined as exposure to a temperature sufficient to freeze the } \\
\text { drug. Statements in parentheses indicate argument by analogy if the data available } \\
\text { did not cover the full temperature range assumed for the investigation. Entries in bold } \\
\text { indicate that the information was based on personal communication to the author. } \\
\text { *T Küpper, unpublished data. } \\
\text {-, no data or not indicated. }\end{array}$} \\
\hline
\end{tabular}

unit, and as such should be unaffected by changes in the ambient temperature. For drugs which recommend storage at a temperature lower than $30^{\circ} \mathrm{C}$, it has been demonstrated that temperature stress of limited duration does not lead to deterioration in the drug. ${ }^{66-68}$ Therefore, such drugs should be safe to transport to extreme climates and should remain stable until climatic control is attainable. If medications are exposed to extreme heat or cold, it is recommended to replace drugs if possible.

Certain drug delivery systems (suppositories, creams, etc) are more sensitive to rises in temperature and it is wise to avoid stocking these if possible. Any drug that contains proteins (eg, insulin) or emulsions will be destroyed by freezing. Gelatin-based fluids with a high molecular weight have a tendency to gel and solidify if stored at lower temperatures. Modern succinylated or urea-crosslinked gelatins have a lower gel melting point and are therefore less prone to this effect. Küpper $e t a l^{67}$ consolidated the available data on the safety of drugs following heat and cold stress in 2006 providing a valuable reference for expedition medical teams. The pertinent findings are summarised in Table 2 . It should be remembered that expiration dates are based upon studies of degradation within the recommended storage temperature range and may be shortened if a drug has been exposed to a temperature outwith this range.

\section{CONCLUSIONS}

There are many considerations when planning the care of patients in extremes of temperature. This is a highly specialised area of medicine that is rapidly evolving, and equipment is being continually developed and improved to aid the management of patients in austere environments. When planning a military or civilian expedition, difficulties should be anticipated and prepared for and where possible climatic control should be sought early. Appropriate clothing and storage facilities for drugs and equipment must be available, particularly during the entry and exit phase of an expedition. Logistical difficulties may limit restocking of equipment or drugs and sufficient contingency should be available. The local region must be thoroughly researched prior to departure with a focus on climate, terrain, geography, hazards, available medical facilities and common local pathologies. All expedition personnel must be of sufficient physical robustness and should be given a medical briefing.

There is a great deal of individual variation in the response to extreme cold or heat. Doctors must do what they can to avoid exposing themselves and their patients to these extremes but must be prepared to mitigate the effects when it cannot be avoided. Unfortunately, there is no clear-cut dose-response relationship between temperature and cognitive function or with duration of exposure. This ambiguity may leave medical planners frustrated. We would advise that if at all possible, the medical team for expeditions should be sufficiently manned to allow for frequent rests and rewarming/cooling of personnel. This would also help mitigate against lapses in concentration and hopefully reduce the incidence of clinical errors. Additionally, close monitoring for signs of depression should be undertaken in any personnel deploying to an extremely cold environment for a prolonged period of time-particularly if deploying over the winter months. If possible, a period of acclimatisation should be undertaken prior to departure for all team members.

Many clinical challenges may be faced by medical personnel caring for patients in extremes of climate. These include but are not limited to: alterations in baseline physiology, altered response to pathological insult and medical intervention, alterations in the functioning characteristics of medical equipment and increased attrition rate of equipment and drugs. Successful expeditionary medical care requires resourcefulness, preparedness and at all times close communications with base medical support.

Contributors Both of the authors were involved in the planning and execution of the article and the lead author (EMH) takes responsibility for the overall content.

Disclaimer While every effort has been taken to present data that have been carefully researched, the reader is advised that any use of drugs or equipment stored or used outside their stated temperature range would be out of license and no claim is made as to the accuracy of the reported effects.

\section{Competing interests None.}

Provenance and peer review Not commissioned; externally peer reviewed.

\section{REFERENCES}

1 Venticinque SG, Grathwohl KW. Critical care in the austere environment: providing exceptional care in unusual places. Crit Care Med 2008;36:\$284-92.

2 http://www.weatherbase.com/weather/weather.php3?s=90098\&refer=\&units=me tric (accessed Sep 2013).

3 http://www.thecoldestjourney.org (accessed Sep 2013).

4 Court A. How hot is Death Valley? Geogr Rev 1949;39:214-20.

5 Mallet ML. Pathophysiology of accidental hypothermia. QJM 2002;95:775-85.

6 Wong KC. Physiology and pharmacology of hypothermia. West J Med 1983;138:227. 
7 Morris DL, Chambers HF, Morris MG, et al. Hemodynamic characteristics of patients with hypothermia due to occult infection and other causes. Ann Intern Med 1985; 102:153-7.

8 Rintamäki H. Human responses to cold. Alaska Med 2007;49(2 Suppl):29-31.

9 Roscher R, Arlock P, Sjöberg T, et al. Effects of dopamine on porcine myocardial action potentials and contractions at 37 degrees $\mathrm{C}$ and 32 degrees C. Acta Anaesthesiol Scand 2001;45:421-6.

10 Mustafa S, Shaikh N, Gowda RM, et al. Electrocardiographic features of hypothermia. Cardiology 2005;103:118-19.

11 Buggy DJ, Crossley AWA. Thermoregulation, mild perioperative hypothermia and post-anaesthetic shivering. Br J Anaesth 2000;84:615-28.

12 Washington DE, Sessler DI, Moayeri A. Thermoregulatory responses to hyperthermia during isoflurane anesthesia in humans. J App/ Physiol 1993;74:82-7.

13 Haman F, Blondin DP, Imbeault M-A, et al. Metabolic requirements of shivering humans. Front Biosci (Schol Ed) 2010;2:1155-68.

14 Matsukawa T, Kurz A, Sessler DI, et al. Propofol linearly reduces the vasoconstriction and shivering thresholds. Anesthesio/ 1995;82:1169-80.

15 Annadata R, Sessler DI, Tayefeh F, et al. Desflurane slightly increases the sweating threshold but produces marked, nonlinear decreases in the vasoconstriction and shivering thresholds. Anesthesiol 1995;83:1205-11.

16 Merridew CG, Fraser SJ. Isoflurane field anaesthesia at extreme temperatures. Anaesthesia 1991;46:1000.

17 Adams T, Covino BG. Racial variations to a standardized cold stress. J App/ Physiol 1958;12:9-12

18 Donaldson GC, Keatinge WR, Näyhä S. Changes in summer temperature and heat-related mortality since 1971 in North Carolina, South Finland, and Southeast England. Environ Res 2003;91:1-7.

19 Atterhög JH, Carlens P, Granberg PO. Cardiovascular and renal responses to acute cold exposure in water-loaded man. Scand J Clin Lab Invest 1975;35:311-17.

20 Danzl DF, Pozos RS. Accidental hypothermia. N Engl J Med 1994;331:1756-60.

21 Staab DB, Sorensen VJ, Fath JJ. Coagulation defects resulting from ambient temperature-induced hypothermia. J Trauma Acute Care Surg 1994;36:634.

22 Krause KR, Howells GA, Buhs CL. Hypothermia-induced coagulopathy during hemorrhagic shock. Am Surg 2000;66:348-54.

23 Cotton BA, Guy JS, Morris JA Jr, et al. The cellular, metabolic, and systemic consequences of aggressive fluid resuscitation strategies. Shock 2006;26:115-21.

24 Mercke $\mathrm{U}$, Håkansson $\mathrm{CH}$. The Influence of temperature on mucociliary activity temperature range $20^{\circ} \mathrm{C}-40^{\circ} \mathrm{C}$. Acta Oto-laryngologica $1974 ; 74: 444-50$.

25 Gautier $\mathrm{H}$, Bonora M. Ventilatory and metabolic responses to cold and hypoxia in intact and carotid body-denervated rats. J App/ Physiol 1992;73:847-54.

26 Liu EH, Dhara SS. Sevoflurane output from the Oxford Miniature Vaporizer in drawover mode. Anaesth Intensive Care 2000;28:532-6.

27 Ralley FE, Wynands JE, Ramsay JG, et al. The effects of shivering on oxygen consumption and carbon dioxide production in patients rewarming from hypothermic cardiopulmonary bypass. Can J Anaesth 1988;35:332-7.

28 Astrup P, Engel K, Severinghaus JW. The influence of temperature and pH on the dissociation curve of oxyhemoglobin of human blood. Scan J Clin Lab Invest 1965:17:515-23.

29 McCunn M, Dutton R. End-points of resuscitation how much is enough? Curr Opin Anaesthesiol 2000;13:147-53.

30 Salmon PA, Griffen WO, Jenson CB, et al. The effect of temperature on intestinal motility. Surgery 1959;46:873-9.

31 De Jesus PV, Hausmanowa-Petrusewicz I, Barchi RL. The effect of cold on nerve conduction of human slow and fast nerve fibers. Neurology 1973;23:1182.

32 Barnard D. The effects of extreme cold on sensory nerves. Ann R Coll Surg Engl 1980;62:180-7.

33 Wakabayashi $\mathrm{H}$, Wijayanto $\mathrm{T}$, Kuroki $\mathrm{H}$, et al. The effect of repeated mild cold water immersions on the adaptation of the vasomotor responses. Int J Biometeorol 2012:56:631-7.

34 Mekjavic I, Dobnikar U, Kounalakis S. The trainability and contralateral response of cold-induced vasodilatation in the fingers following repeated cold exposure. Eur J Appl Physiol 2008;104:193-9.

35 Reynolds LF, Mekjavic IB, Cheung SS. Cold-induced vasodilatation in the foot is not homogenous or trainable over repeated cold exposure. Eur J Appl Physiol 2007;102:73-8.

36 Keramidas M, Musizza B, Kounalakis S. Enhancement of the finger cold-induced vasodilation response with exercise training. Eur J Appl Physiol 2010;109:133-40.
37 Giesbrecht G, Arnett J, Vela E. Effect of task complexity on mental performance during immersion hypothermia. Aviat Space Environ Med 1993;64(3 Pt 1):206-11.

38 Palmai G. Psychological observations on an isolated group in Antarctica. B J Psych 1963;109:364-70.

39 Mullin CS. Some psychological aspects of isolated Antarctic living. Am J Psych 1960;117:323-5.

40 Barabasz M, Barabasz AF, Mullin CS. Effects of brief Antarctic isolation on absorption and hypnotic susceptibility-preliminary results and recommendations: a brief communication. Int J Clin Exp Hypn 1983;31:235-8.

41 Reed HL, Reedy KR, Palinkas LA, et al. Impairment in cognitive and exercise performance during prolonged antarctic residence: effect of thyroxine supplementation in the polar triiodothyronine syndrome. J Clin Endocrinol Metab 2001;86:110-16

42 Le Scanff C, Larue J. How to measure human adaptation in extreme environments: the case of Antarctic wintering-over. Aviat Space Environ Med 1997;68:1144-9.

43 Gregson RAM. Monitoring cognitive performance in Antarctica. New Zealand Antarctic Record 1978;13:24-32.

44 Hodgdon JA, Hesslink RL, Hackney AC, et al. Norwegian military field exercises in the arctic: cognitive and physical performance. Arctic Med Res 1991;50(Suppl 6):132-6.

45 Baddeley AD, Cuccaro WJ, Egstrom GH, et al. Cognitive efficiency of divers working in cold water. Hum Factors 1975;17:446-54.

46 Stang P. Diver performance in cold water. Hum Factors 1970;12:391-9.

47 Enander A. Effects of moderate cold on performance of psychomotor and cognitive tasks. Ergonomics 1987;30:1431-45.

48 Thomas J, Ahlers S. Cold-induced impairment of delayed matching in rats. Behav Neural Biol 1991;55:19-30.

49 Coleshaw SR, Van Someren RN, Wolff AH, et al. Impaired memory registration and speed of reasoning caused by low body temperature. J App/ Physiol 1983;55:27-31.

50 Gunderson EK. Emotional symptoms in extremely isolated groups. Arch Gen Psych 1963;9:362-8

51 Gunderson EK. Mental health problems in Antarctica. Arch Environ Health 1968:17:558-64.

52 Leon GR, McNally C, Ben-Porath YS. Personality characteristics, mood, and coping patterns in a successful north pole expedition team. J Res Pers 1989;23:162-79.

53 Rauch TM, Lieberman HR. Tyrosine pretreatment reverses hypothermia-induced behavioural depression. Brain Res Bull 1990;24:147-50.

54 Kellogg DL. In vivo mechanisms of cutaneous vasodilation and vasoconstriction in humans during thermoregulatory challenges. J App/ Physiol 2006;100:1709-18.

55 Alzeer A, Al-Arifi A, Warsy A, et al. Nitric oxide production is enhanced in patients with heat stroke. Intensive Care Med 1999;25:58-62.

56 Akhtar MJ, al-Nozha M, al-Harthi S, et al. Electrocardiographic abnormalities in patients with heat stroke. Chest 1993;104:411-14.

57 Grogan H, Hopkins PM. Heat stroke: implications for critical care and anaesthesia. Br J Anaesth 2002;88:700-7.

58 Francesconi RP, Willis JS, Gaffin SL, et al. On the trail of potassium in heat injury. Wilderness Environ Med 1997;8:105-10.

59 World MJ, Booth TC. Iraq: the environmental challenge to HM land forces. Clin Med 2008;8:399-403.

60 Franks NP, Lieb WR. Temperature dependence of the potency of volatile general anesthetics: implications for in vitro experiments. Anesthesiology 1996;84:716-20.

61 Imrie MM, Hall GM. Body temperature and anaesthesia. Br J Anaesth 1990;64:346-54.

62 Dematte JE, O'Mara K, Buescher J, et al. Near-fatal heat stroke during the 1995 heat wave in Chicago. Ann Intern Med 1998;129:173-81.

63 Smith JE. The pathophysiology of exertional heatstroke. J R Nav Med Serv 2004:90:135-8.

64 Mackworth NH. Researches on the measurement of human performance. Med Res Council Spec Rep Ser No 268 1950:156.

65 Ramsey J, Dayal D. Heat stress limits for the sedentary worker. AlHA J 1975;36:259-65

66 Johansen RB, Schafer NC, Brown PI. Effect of extreme temperatures on drugs for prehospital ACLS. Am J Emerg Med 1993;11:450-2.

67 Küpper TEAH, Schraut B, Rieke B, et al. Drugs and drug administration in extreme environments. J Travel Med 2006;13:35-47.

68 Hogerzeil HV, Battersby A, Srdanovic V, et al. Stability of essential drugs during shipment to the tropics. BMJ 1992;304:210-12. 